\title{
Electromyography and Nerve Conduction Studies in Friedreich's Ataxia and Autosomal Recessive Spastic Ataxia of Charlevoix-Saguenay (ARSACS)
}

\author{
J.P. BOUCHARD, A.BARBEAU, R. BOUCHARD AND R. W.BOUCHARD
}

SUMMARY: Twenty four ataxic patients were investigated with electromyography and nerve conduction studies. They were divided in two groups according to the area they came from, the evolution of the disease, and the clinical signs. Group I patients from the Rimouski area displayed all the clinical and electrophysiological signs of Friedreich's ataxia. Group II comprised patients who presented with a new syndrome known as the autosomal recessive spastic ataxia of CharlevoixSaguenay (ARSACS). Although the clini-

RÉSUMÉ: Vingt-quatre patients ataxiques divisés en deux groupes selon le lieu d'origine, l'évolution et les signes cliniques, ont subi un électromyogramme et des épreuves de conduction nerveuse. Les patients du Groupe I originaires de la région de Rimouski, montrent toutes les caractéristiques cliniques et électrophysiologiques de l'ataxie de Friedreich telles que déjà publiées dans la littérature médicale. Les patients du Groupe II présentent un syndrome original décrit sous le nom d'ataxie spastique familiale de Charlevoix- cal evolution was better in the latter, there were more electromyographic signs of denervation and the motor conduction velocities were slower. Both groups showed identical and important abnormalities in sensory nerve conduction.

The results of electrophysiological studies in spastic ataxia have not been reported to our knowledge. They underline the place of spastic ataxia as distinct from Friedreich's ataxia, spastic paraplegia, and the known familial neuropathies.

Saguenay. Bien que l'évolution en soit moins sévère, les signes de dénervation à l'électromyogramme et le ralentissement des vitesses de conduction motrice sont beaucoup plus marqués. Les deux groupes ont des anomalies sévères et identiques de la conduction sensitive.

Les résultats que nous rapportons dans l'ataxie spastique familiale la distinguent nettement d'une part de l'ataxie de Friedreich et de la paraparésie spastique, et d'autre part des neuropathies familiales.
From l'Hôpital de l'Enfant-Jésus, Quebec City, and the Clinical Research Institute of Montreal.

Reprint requests for the complete supplement on Friedreich's Ataxia (Phase Two, part Two) to:

Dr. André Barbeau, Clinical Research Institute of Montreal, 110 Pine Avenue West, Montreal, Quebec. Canada, H2W IR7.

\section{INTRODUCTION}

In view of the large number of clinical descriptions concerned with genetic, pathological, and electrophysiological studies of hereditary ataxias, there is confusion in classes, types, groups, forms, and entities. The valuable effort of Bell and Carmichael to gather and classify the already numerous records up to 1939 has been recognized. In their chapter on the differentiation of clinical types, they noted that Friedreich's ataxia and spastic ataxia are often encountered in the same kindreds and they suggested that the same gene could be responsible, although modified in some way. Clinical, genetic, and biochemical studies of hereditary ataxias in Québec (Bouchard 1978, Barbeau, 1978) support this view, but the electrophysiological findings in the peripheral nervous system (PNS) bring evidence in favor of their differentiation.

Electrophysiological studies were part of the investigation carried out on two groups of ataxic patients originating from different regions of Québec: The first group of patients from the Rimouski area had Friedreich's ataxia (see: Bouchard et al. in this issue). The second group had the autosomal recessive spastic ataxia of Charlevoix-Saguenay (ARSACS) described by Bouchard et al. in 1978 .

Several electrophysiological studies of the peripheral nervous system have disclosed the main characteristics of Friedreich's ataxia. (Dyck and Lambert, 1968; McLeod, 1971; Oh and Halsey, 1973; Dunn, 1973; Salisachs, 1975; Peyronnard, 1976). These are: (1) On EMG, subtle signs of denervation evidenced by rare 
fibrillations at rest, an increased number of polyphasic action potentials of long duration and low amplitude, and a reduced recruitment pattern. These signs are more obvious in distal muscles especially in the lower limbs. (2) Slightly reduced motor conduction velocities. (3) Absence of, or abnormal sensory nerve action potentials in all the cases.

Familial spastic ataxia was the term used by Bell and Carmichael in 1939 to identify a large number of cases of hereditary spinocerebellar degeneration which did not fit the criteria of Friedreich's ataxia or of Strumpell's spastic paraplegia. Dyck (1975), Shimono (1977), and McLeod (1977) have described EMG and nerve conduction studies in spastic paraplegia but little has been said about familial spastic ataxia. In two recent papers on the subject (Hogan, 1977; Bergstedt, 1962) there are no electrophysiological data on the peripheral nervous system. It appeared interesting to compare the results of EMG and nerve conduction studies in both a large kinship of Friedreich's ataxia and the autosomal spastic ataxia of CharlevoixSaguenay, and with the data in the literature.

\section{SUBJECTS,}

\section{MATERIALS AND METHODS}

Group 1 consists of nine patients from the Rimouski area from 17 to 28 years of age, with symptoms of ataxia for 11 to 22 years. Their clinical features are reported elsewhere in this journal.

Group II consists of 15 patients, eleven of which were included in the original description of ARSACS cases (Bouchard et al. 1978). Their age ranged from 12 to 43 years and all of them had symptoms of ataxia from the time they began to walk. Ten walked alone, four needed help, and the oldest patient was no longer standing because of severe deformity of the feet. She has resumed some walking after corrective surgery. Each group of patients was fairly homogeneous in itself and distinct from the other with respect to age of onset, the evolution, the ocular findings, and the presence, only in the former, of truncal ataxia, areflexia, scoliosis, and cardiomyopathy.

All patients but one (A.J., Group II) were tested by the same electromyographist in a room at normal temperature (about $22^{\circ} \mathrm{C}$ ) when lying on a wooden table, using a TECA TE4 two channels electromyograph with built-in averager and NS6 nerve stimulator.

Recordings were done on proximal and distal muscles of upper and lower limbs on one side. Bipolar needle electrodes were used. Muscles were studied at rest for insertional and spontaneous activity and during minimal and maximal voluntary contraction.

Motor conduction velocities (MCV) of median, ulnar, and peroneal nerves were studied with the EMG needle inserted in abductor pollicis brevis, abductor digiti quinti, and extensor digitorum brevis (EDB) muscles respectively. The needle was moved to obtain the potential with the largest amplitude and a sharp initial negative deflection. MCV's were calculated when stimulation was possible at two different sites on a nerve. In the case of the youngest patient in Group II, MCV was done only for the peroneal nerve.
Latencies of motor responses were measured following stimulation of ulnar and median nerves at the wrist. The peroneal nerve was stimulated at the ankle, but when it was impossible to record in EDB, the nerve was stimulated at the head of the fibula and responses recorded in the tibialis anterior muscle.

Sensory nerve action potentials (SAP) were recorded with surface electrodes placed at the wrist over the median and ulnar nerves and evoked by metallic digit electrodes on the index and little finger respectively (Dawson and Scott, 1949). Attempts were made to find antidromic SAP's in all cases.

\section{RESULTS \\ A) Electromyographic Studies}

EMG findings are summarized in Table I. In Group I, the spontaneous activity was characterized by an inability to relax especially the proximal muscles. This was recorded as high frequency discharges following insertion of the needle electrode or voluntary muscle contraction. Signs of denervation, such as fibrillations or positive sharp waves, were rare in this group. In Group II, however, the spontaneous activity was mainly
TABLE I

Electromyography

\begin{tabular}{|c|c|c|c|c|c|c|c|c|}
\hline & \multicolumn{3}{|c|}{ At Rest } & \multicolumn{2}{|c|}{$\begin{array}{c}\text { Action } \\
\text { Potentials }\end{array}$} & \multicolumn{3}{|c|}{ Recruitment } \\
\hline & 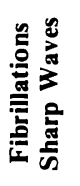 & 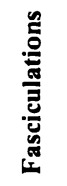 & 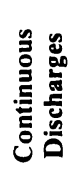 & 苞䒿 & 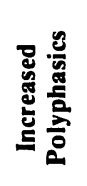 & 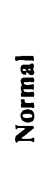 & 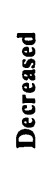 & 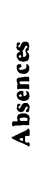 \\
\hline \multicolumn{9}{|l|}{ GROUP I (Friedreich) } \\
\hline $\begin{array}{l}\text { Deltoid or Biceps (9) } \\
\text { Abd. Pol. Brevis (9) } \\
\text { Abd. Dig. Quinti (8) } \\
\text { Tibialis Anterior (3) } \\
\text { Ext. Dig. Brevis (9) }\end{array}$ & 1 & $\begin{array}{l}1 \\
1\end{array}$ & $\begin{array}{l}6 \\
1 \\
1 \\
1\end{array}$ & $\begin{array}{l}1 \\
3 \\
1 \\
3\end{array}$ & $\begin{array}{l}2 \\
2 \\
3 \\
1 \\
2\end{array}$ & 2 & $\begin{array}{l}7 \\
9 \\
8 \\
2 \\
8\end{array}$ & $\begin{array}{l}1 \\
1\end{array}$ \\
\hline $\begin{array}{l}\text { GROUP II (ARSACS) } \\
\text { Deltoid or Biceps (13) } \\
\text { Abd. Pol. Brevis (14) } \\
\text { Abd. Dig. Quinti (14) } \\
\text { Tibialis Anterior (14) } \\
\text { Ext. Dig. Brevis (15) }\end{array}$ & $\begin{array}{l}2 \\
2 \\
3 \\
8\end{array}$ & $\begin{array}{l}1 \\
4 \\
2 \\
2\end{array}$ & & $\begin{array}{l}2 \\
2 \\
2 \\
3 \\
5\end{array}$ & $\begin{array}{c}6 \\
8 \\
10 \\
12 \\
3\end{array}$ & $\begin{array}{l}3 \\
2 \\
1\end{array}$ & $\begin{array}{c}10 \\
12 \\
13 \\
14 \\
7\end{array}$ & 8 \\
\hline
\end{tabular}


recorded as fibrillations and fasciculations in distal muscles. Insertional activity was increased and doublets were seen infrequently in the two groups.

During voluntary contraction, motor unit action potentials (MUAP) recorded in Group I were sometimes of low amplitude in the distal muscles, with occasional increases in the number of polyphasic potentials. duration and amplitude of MUAP. Polyphasic potentials were seen much more often in this group. In both groups, recruitment was incomplete in almost all muscles. Note that activity could be recorded from EDB muscles in 8 patients out of 9 in Group I and in only 7 patients out of 15 in Group II.

\section{B) Motor Nerve Conduction}

Distal motor latencies obtained from the median, ulnar, and peroneal nerves were within normal limits with few exceptions in Group I, but clearly prolonged in most instances in Group II. The results are tabulated for both groups in Table II and graphically Fig. I for peroneal nerve. MCV's were found to be slightly reduced in these nerves in Group I, and much slower in Group II (ARSACS), as shown in Table II and figure 2. For peroneal nerve in Group II (ARSAC), distal latency was obtained in 7 instances and MCV in only five of the 15 cases.

The normal values for latency et MCV were originally derived from the literature (Kaeser 1970) and found Group II showed wide variations in presented for Group II (ARSACS) in

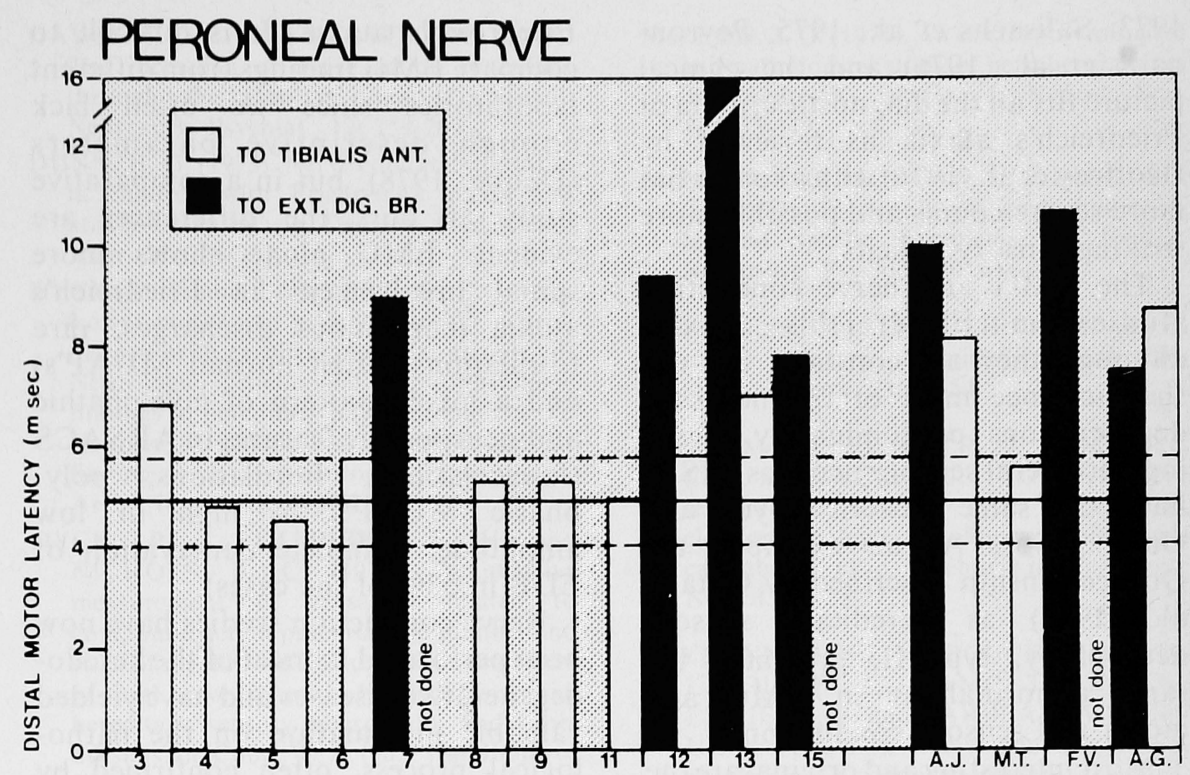

CASE NUMBER

Figure I-Distal motor latencies of peroneal nerve to EDB (black columns) and tibial anterior muscle (white columns) in 15 cases of ARSACS (Group II). Horizontal lines show normal mean and standard deviation of latency to EDB. From there, motor latencies could be calculated only in seven cases applicable to normal subjects in our laboratory (Table II).

\section{C) Sensory Nerve Conduction}

Of the twenty three patients undergoing studies of evoked sensory action potentials when stimulating from one little finger, none presented a dectectable response over the ulnar nerve. A SAP was recorded on two occasions over the median nerve after stimulation of the index finger; in a 18
TABLE II

Motor Nerve Conduction

\begin{tabular}{|c|c|c|c|c|c|c|}
\hline \multirow[t]{2}{*}{ Group } & \multirow[t]{2}{*}{ Nerve } & \multirow[t]{2}{*}{$\mathbf{N}$} & \multicolumn{2}{|c|}{ Latency (msec) } & \multicolumn{2}{|c|}{ Velocity (m/sec) } \\
\hline & & & Mean & Range & Mean & Range \\
\hline \multirow[t]{2}{*}{1} & Median & 9 & 3.51 & $3.0-4.6$ & 50.05 & $41.3-54.3$ \\
\hline & Ulnar & 8 & 2.70 & $2.0-3.0$ & 50.70 & $44.7-54.7$ \\
\hline (FRIEDREICH) & Peroneal & 9 & 5.75 & $4.1-10.5$ & 40.11 & $32.4-49.1$ \\
\hline \multirow{3}{*}{$\begin{array}{c}\text { II } \\
(\mathrm{ARSACS})\end{array}$} & Median & 14 & 5.98 & $3.7-11.4$ & 36.56 & $29.2-44.1$ \\
\hline & Ulnar & 15 & 4. 12 & $2.8-5.2$ & 37.11 & $24.4-46.2$ \\
\hline & Peroneal & 15 & 10.00 & $\begin{array}{c}7.4-16.0 \\
(7 \text { out of } 15)\end{array}$ & 27.04 & $\begin{array}{c}22.3-35.8 \\
(5 \text { out of } 15)\end{array}$ \\
\hline \multirow[t]{2}{*}{ Normal } & Median & 120 & 3.4 & $2.0-4.3$ & 56 & $50-68$ \\
\hline & Ulnar & 120 & 2.7 & $1.8-3.4$ & 58 & $49-66$ \\
\hline (Kaeser 1970) & Peroneal & 120 & 5.0 & $3.0-7.0$ & 50 & $42-62$ \\
\hline
\end{tabular}

year old patient of Group I (latency 3.6 msec, amplitude $2 \mathrm{uV}$ ); and in a 34 year old patient of Group II (latency 5.0 msec, amplitude $3 \mathrm{uV}$ ). The normal values for median nerve in our laboratory are less than $3.2 \mathrm{msec}$ for the latency and more than $10 \mu \mathrm{V}$ for the amplitude.

Antidromic stimulation of the ulnar nerve produced a detectable SAP in only these two cases. The Group I patient showed a response of $10 \mu \mathrm{V}$ after 4.0 msec and the Group II patient produced a potential of $15 \mu \mathrm{V}$ after 8.5 msec.

Antidromic stimulation of the median nerve also produced a response in three other cases ( 2 in Group I and one in Group II) with latencies of $3.7,5.5$, and $4.5 \mathrm{msec}$ and amplitude of 5,10 , and $5 \mu \mathrm{V}$ respectively.

\section{DISCUSSION}

In the first group of patients reported here, electrophysiological studies of the PNS showed results similar to published data on Friedreich's ataxia (Preswick, 1968; Dyck and Lambert, 1968; McLeod, 1971; Oh and Hasley, 1973; Dunn, 
1973; Salisachs et al., 1975; Peyronnard et al., 1976) and the clinical picture fits all the diagnostic criteria of Friedreich's ataxia as reviewed by Geoffroy et al. (1976) with a somewhat more severe course and possibly more striking sensory deficits.

The EMG and nerve conduction studies in Friedreich's ataxia, although they are constant, are not specific since most of the neuronal degenerations predominantly affecting peripheral sensory neurons (HSN) have the same pattern (Dyck and Ohta, 1975). As an example, the Québec kinship described by Ohta et al. (1973) as hereditary sensory neuropathy, type II, presented the same abnormalities in EMG and motor and sensory conductions.

Most interesting and original are the results of electrophysiological studies of the PNS in Group II (ARSACS). For years ARSACS had been diagnosed as Friedreich's ataxia, spastic paraplegia, or as a "forme de passage" between these better known entities, because the evolution and some clinical signs of the patients were reminiscent of both. EMG and nerve conduction studies support the individualisation of ARSACS.

In ARSACS, the EMG has shown more denervation signs than in
Friedreich's ataxia. It is difficult to compare EMG findings from different laboratories since we often lack enough descriptive parameters (Daube, 1978), but in a comparative study as ours the differences are evident. EMG alone shows more spinal involvement in Friedreich's ataxia (continuous discharges, rare fibrillations, often normal MUAP's) and a mixed pattern of myelopathic and neuropathic features in ARSACS (fasciculations, fibrillations, polyphasic MUAP's of high or low amplitude, complete denervation of EDB in $53 \%$ of the cases).

Nerve conduction studies have now been performed in most of the heredodegenerative diseases and have yielded valuable information on the pathological process, often confirmed by biopsy material.

Sensory nerve action potentials were similarly abnormal in both our groups of patients, but were not unlike those found in hereditary sensory neuropathies and familial hypertrophic neuropathies. Only sophisticated studies of compound action potentials of sural nerve in vitro can show the population of sensory fibers more involved (Dyck et al., 1971, Ohta et al., 1973, Dyck and Ohta, 1975) and one would expect that they are the
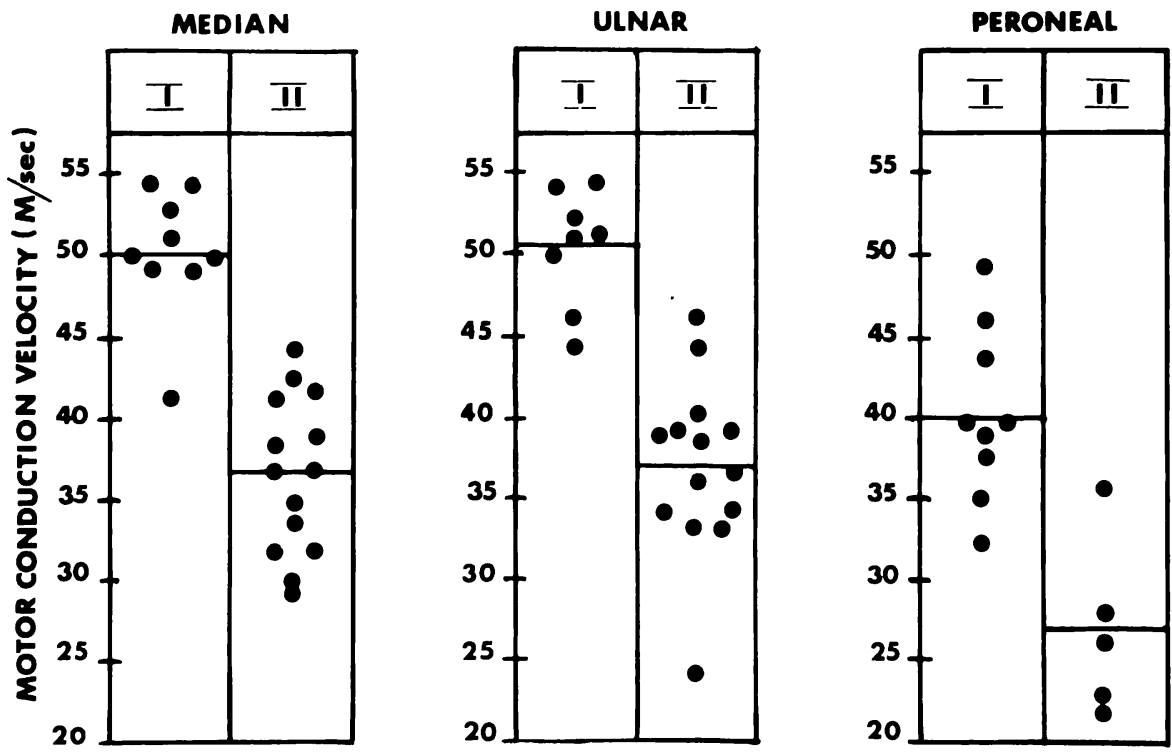

Figure 2-Motor conduction velocities in median, ulnar, and peroneal nerves in Group I (Friedreich's ataxia) and in Group II (ARSACS). Horizontal lines represent the mean of the group.

large myelinated ones (A $\alpha$ ) when SAP cannot be obtained in vivo. In four cases of ARSACS, we performed a sural nerve biopsy which showed no large myelinated fibers and no onion bulb formation upon microscopic examination. (See also Peyronnard et al, this issue).

Motor conduction velocities have been found within or just below the normal limits in HSN's (Dyck and Ohta, 1975) and Friedreich's ataxia (vide supra). In spastic paraplegia, they are reported as normal (Dyck, 1975; McLeod, 1977). In most cases of familial hypertrophic neuropathy, MCV's are, on the average, less than half the normal values (Yudell et al., 1965; Dyck and Lambert, 1968).

Although ARSACS patients had little muscle weakness, distal amyotrophy of legs, feet, and hands was present in most of the cases and especially marked in the hands in some families. No enlarged nerves were found and MCV's were reduced, on the average, by one third of normal values. It is therefore obvious that ARSACS cannot be assimilated to Charcot-Marie-Tooth disease or its variant, the Roussy-Lévy syndrome, if one considers also the autosomal recessive transmission, the clinical picture, and the pathological findings.

In Friedreich's ataxia there is no worsening of the conduction velocities with the duration of the disease (Dunn, 1973; Salisachs, 1975; Peyronnard, 1976) and the degenerative process seems to be more active in large myelinated axons of cutaneous nerves, and to a lesser degree in deep sensation and large motor neurons (Dyck and Ohta, 1975).

In ARSACS there is more involvement of these large motor neurons according to the EMG and MCV's results, but there is comparable damage to the large myelinated fibers of cutaneous nerves. Despite this apparently greater peripheral involvement, the functional status is better in ARSACS since most of the patients can still walk, with some help, in their forties. As in Friedreich's ataxia and other heredo-degenerative disorders, motor and sensory conduction abnormalities are not age related in ARSACS, although patients have 
not been followed over a period of many years.

The early involvement of nerve conduction velocities (Dyck and Lambert, 1968; Dunn, 1973; Peyronnard, 1976) and their relative specificity seem to provide, up to now, the best objective criterion to differentiate certain heredodegenerative disorders and to screen members at risk in the affected families.

\section{ACKNOWLEDGEMENTS}

These studies were supported by grants from r'Association Canadienne de l'Ataxie de Friedreich. We wish to thank Dr. M. Filion for his advice and Mrs. A. Labrecque for her assistance. Dr. Y. Lamarre did the EMG and nerve conduction studies in one case (A.J.).

\section{REFERENCES}

BARBEAU, A. (1978). Friedreich's ataxia 1978: An overview. Can. J. Neurol. Sci., 5: 161165.

BELL. J. M. and CARMICHAEL, E. A. (1939). On hereditary ataxia and spastic paraplegia. In: Treasury of Human Inheritance, Vol. 4, Cambridge Press, London, pp 141-284.

BERGSTEDT, M., JOHANSSON, S. and MULLER, R. (1962). Hereditary spastic ataxia with central retinal degeneration and vestibular impairment. Neurol., 12: 124-132.

BOUCHARD, J. P., BARBEAU, A., BOUCHARD, R. and BOUCHARD, R. W. (1978). Autosomal recessive spastic ataxia of Charlevoix-Saguenay. Can. J. Neurol. Sci., 5: 61-70.

DAUBE, J. R. (1978). The description of motor unit potentials in electromyography. Neurol., 623-625.
DAWSON, G. D. and SCOTT, J. W. (1949). The recording of nerve action potentials through the skin in man. J. Neurol. Neurosurg. Psychiat., 12: 259-267.

DUNN, H. G. (1973). Nerve conduction studies in children with Friedreich's ataxia and ataxia-telangiectasia. Develop. Med. Child. Neur. 15: 324-337.

DYCK, P. J. and LAMBERT, E. H. (1968), Lower motor and primary sensory neuron diseases with peroneal muscular atrophy. 1 . Neurologic, genetic and electrophsiologic findings in hereditary polyneuropathies. II. Neurologic, genetic and electrophysiologic findings in various neuronal degenerations. Arch. Neurol. 18: 603-625.

DYCK, P. J., LAMBERT, E. H. and NICHOLS. P. C. (1971). Quantitative measurement of sensation related to compound action potential and number and sizes of myelinated and unmyelinated fibers of sural nerve in health, Friedreich's ataxia, hereditary sensory neuropathy and tabes dorsalis. In: Cobb, W. A. (ed.): Handbook of Electroencephalography and Clinical Neurophysiology. Vol. 9, Amsterdam, Elsevier Publishing Co., pp 83-117.

DYCK, P. J. and OHTA, M. (1975). Neuronal atrophy and degeneration predominantly affecting peripheral sensory neurons. In: Peripheral Neuropathy. Edited by Dyck, Thomas, Lambert, pp 791-824, W. B. Saunders and Co. (Phil.).

DYCK, P. J. (1975). Inherited neuronal degeneration and atrophy affecting peripheral motor, sensory, and autonomic neurons. Ibidem, pp 825-867.

HOGAN, G. R. and BAUMAN, M. L. (1977). Familial spastic ataxia: Occurrence in childhood. Neurol. 27: 520-526.

KAESER, H. E. (1970). Nerve conduction velocity measurements. In: Handbook of clinical Neurology, Vol. VIl. Diseases of Nerves (part I) pp 116-196. P. J. Vinken and G. W. Bruyn editors. North-Holland Publishing Co. Amsterdam.
McLEOD. J. G. (1971). An electrophysiological and pathological study of peripheral nerves in Friedreich's ataxia. J. Neurol. Sci., 12: 333-349.

McLEOD, J. G. MORGAN, J. A. and REYE, C. (1977). Electrophysiological studies in familial spastic paraplegia. J. Neurol. Neurosurg. Psychiat. 40: 611-615.

OH, S. J. and HASLEY, J. H. (1973). Abnormality in nerve potentials in Friedreich's ataxia. Neurol. 23: 52-54.

OHTA, M., ELLEFSON, R. D., LAMBERT, E. H. and DYCK, P. J. (1973). Hereditary sensory Neuropathy, Type 11. Clinical, electrophysiologic, histologic and biochemical studies of a Québec kinship. Arch. Neurol. 29: 23-27.

PEYRONNARD, J. M., BOUCHARD, J. P., LAPOINTE, L., LAMONTAGNE, A., LEMIEUX, B. and BARBEAU, A. (1976). Nerve conduction studies and electromyography in Friedreich's ataxia. Can. J. Neurol. Sci., 3: 313-318.

PRESWICK, G. (1968). The neuropathy of Friedreich's ataxia. Proc. Aus. Ass. Neurologists, 5: 69-71.

SALISACHS, P., CODINA, M. and PRADAS, J. (1975). Motor conduction velocity in patients with Friedreich's ataxia. J. Neurol. Sci., 24: 331-337.

SHIMONO, M., OHTA, M. and KUROWA, Y. (1977). Spastic paraplegia with neurogenic amyothrophy manifesting ballooned axons in sural nerve. Acta Neuropath. (Berl.), 39: 9-12.

YUDELL, A., DYCK, P. J. and LAMBERT, E. H. (1965). A kinship with the RoussyLévy Syndrome. A clinical and electrophysiologic study. Arch. Neurol., 13: 432440 . 
https://doi.org/10.1017/S0317167100119614 Published online by Cambridge University Press 


\section{Every leading}

pharmaceutical house has its own claim

\section{to fame.}

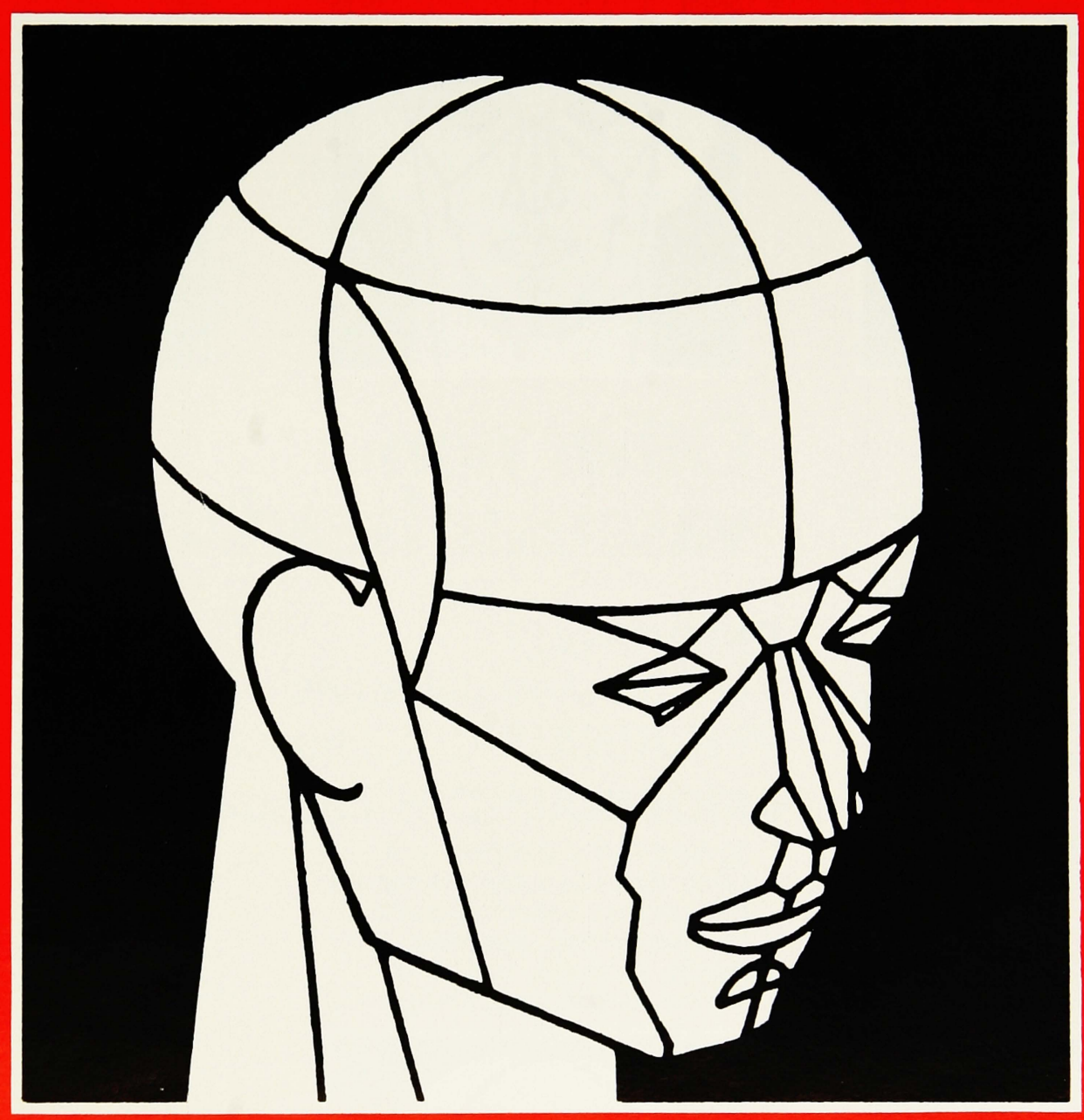

Ours is headache therapy.

\section{SANDOZ}

The leader in headache research and treatment. 
Vascular headaches

of the migraine type

ICAFERGOT ${ }^{\circledR}$ tablets [T GYNERGEN ${ }^{\circledR}$ tablets and injections

Symptomatic treatment of classic, common, or cluster migraine.

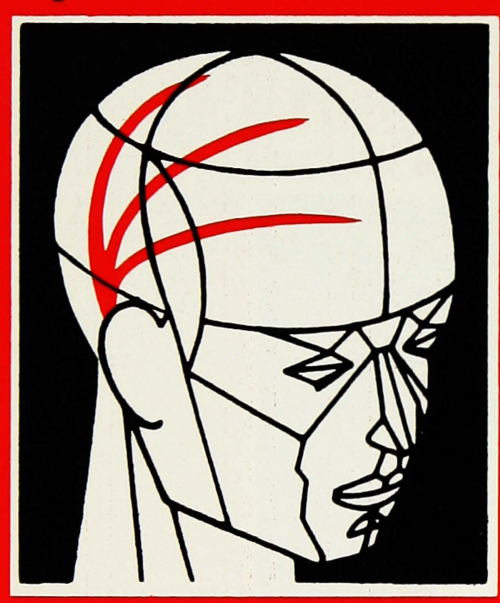

Tension

headaches

(muscle contraction)

- FIORINAL

tablets and capsules

(i) FIORINAL ${ }^{-}-\mathrm{C} 1 / 4$

capsules

(1)FIORINAL두 1/2

capsules

Symptomatic treatment of

muscle contraction headache

(tension headache).

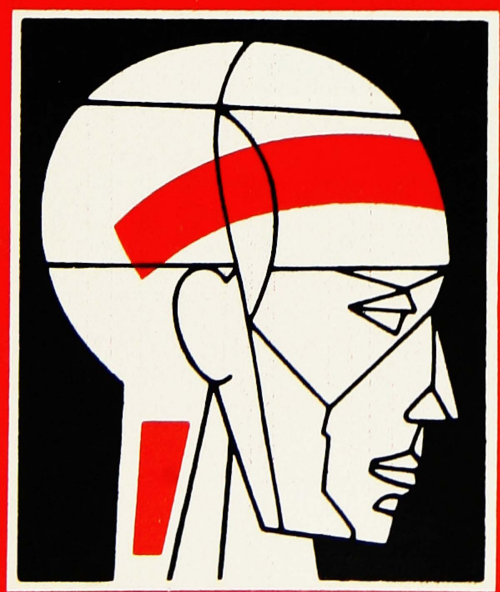

ISANDOMIGRANं

tablets

ISANSERT ${ }^{\circledR}$ tablets

Prophylactic treatment of

frequent, recurring vascular

headaches.

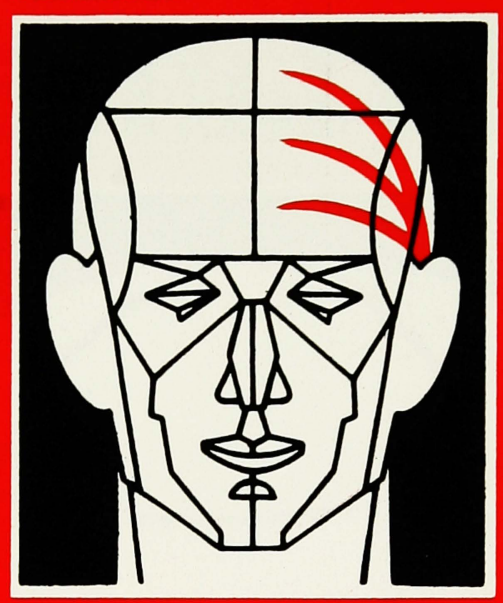

Other non-

vascular headaches
- CAFERGOT`-PB

tablets and

\section{suppositories}

Symptomatic treatment of classic, common, or cluster migraine (accompanied by nervous tension, nausea and vomiting).

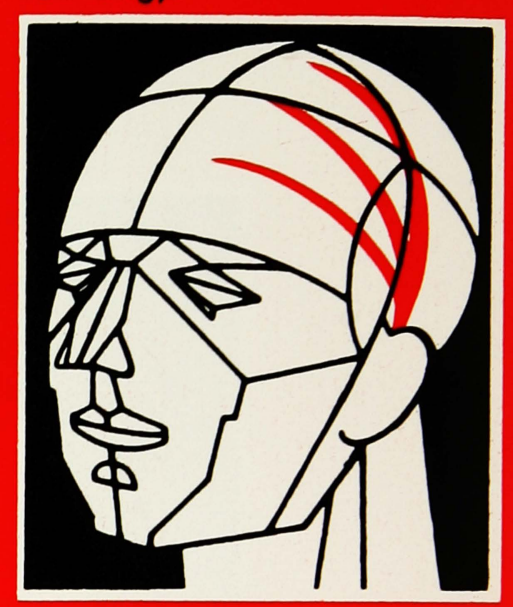

